\title{
Future directions in modelling physical-biological interactions
}

\author{
Charles G. Hannah* \\ Bedford Institute of Oceanography, Box 1006, Dartmouth, Nova Scotia B4A 3M2, Canada
}

\begin{abstract}
Reflection on 5 yr of deliberations of the International Council for the Exploration of the Sea (ICES) Working Group on Modelling Physical-Biological Interactions and the discussions at the workshop on 'Future Directions in Modelling Physical-Biological Interactions' has led to 3 broad themes concerning future work in the field. Firstly, model validation, the rigorous assessment of the level of confidence in the model predictions, is crucial for any model that will be used for practical applications. Secondly, determining the level of model complexity required to capture the essential features of the problem being addressed is an open problem. Finally, all the problems are multidisciplinary and there is a need for more integration of physics, chemistry and biology, on the one hand, and observationalists, experimentalists and modellers, on the other. The process of model validation provides a framework for connecting these themes.
\end{abstract}

KEY WORDS: Physical-biological interactions $\cdot$ Validation $\cdot$ Complexity $\cdot$ Integration

\section{INTRODUCTION}

Numerical simulation of plankton in the ocean is a rapidly growing field. The community has gradually accepted the fact that the highly variable dynamics of the physical, chemical and biological components of the ocean necessitate modelling (or simulation) to improve our understanding of the marine environment, to extrapolate beyond the range of observational experience and to explore scenarios to assist in management decisions. As a result, simulation is a core element of the scientific activities of international programs such as GEOHAB (www.jhu.edu/scor/GEOHABfront.htm), GLOBEC (www.globec.org), IMBER (www.imber.info) and SOLAS (www.uea.ac.uk/env/solas).

The International Council for the Exploration of the Sea (ICES) Working Group on Modelling PhysicalBiological Interactions (WGPBI) is concerned with the evaluation and development of the modelling tools required to increase the understanding of the interaction between the living resources in the sea and their ambient physical and abiotic environment. The members of the group work on issues covering a broad spectrum including fish recruitment, harmful algal blooms, coastal eutrophication, understanding marine ecosystem dynamics and estimating the impact of climate change on the marine environment. The application of the modelling ranges from providing advice to management to a more academic quest for knowledge.

This paper provides a synthesis of the major themes that have emerged from $5 \mathrm{yr}$ of deliberations of the WGPBI (ICES 2001, 2002, 2003, 2004a, 2005, Hannah 2003) and discussions at the recent workshop on 'Future Directions in Modelling Physical-Biological Interactions' (WKFDPBI; ICES 2004b, Peters \& Hannah 2006). With such a diverse group one quickly realises that beautiful conceptual frameworks integrating all of the modelling applications break down in the face of the realities of modelling site-specific problems for particular practical applications. Nevertheless, 3 themes arise time and again: (1) Model validation: Validation is crucial for any model that will be used for practical applications or to provide advice. For any application, there needs to be a rigorous assessment of the level of confidence in the model predictions and of the conditions that can cause the model to fail. 
(2) Model complexity: There is general agreement that the key modelling challenge is to determine the level of detail necessary to capture the essential features relevant to the problem being addressed. However, there are no generally accepted methods for determining this level of detail for any particular application (deYoung et al. 2004).

(3) Integration: All the problems are multidisciplinary and thus there is a need for more integration of physics, chemistry and biology in the models, on the one hand, and the involvement of observationalists and experimentalists along with the modellers, on the other.

In this context modelling refers to dynamical models not statistical models.

The phrase 'physical-biological interactions' (PBI) is used here to cover the entire range of processes influencing the dynamics of planktonic organisms in the ocean. This choice of name for the working group was an inspired one. It has provided a home where a very diverse group of scientists are able to consider the issues and problems that are common across the applications rather than focus on the details that distinguish them.

\section{MODEL VALIDATION AS A FRAMEWORK}

The phrase 'model validation' can mean different things to different people. Consider the operational definition of Dee (1995, p. 4):

Validation of a computational model is the process of formulating and substantiating explicit claims about the applicability and accuracy of computational results, with reference to the intended purposes of the model as well as to the natural systems it represents.

This definition accepts that model validation is a process rather than a yes/no decision. The 'ecological Turing test' of Woods (2002) is an equivalent view of validation, although expressed in very different terms. In either case, validation has the potential to provide a framework for future directions in modelling physicalbiological interactions and to link the 3 broad themes identified above. A few examples are given below.

Systematic improvement of any model requires the ability to diagnose the sources of error, rank them by importance and quantify the improvement. For any model of more than modest complexity, evaluating the sources of error requires a clear understanding of the relationship between (1) the model's state variables and the observed quantities and (2) the model's biological parameters and the physiological rate constants measured in the laboratory or field. Achieving this understanding requires substantial discussion among field observationalists, modellers and laboratory ex- perimentalists. This is a new variant of the old problem of the relationship between laboratory experiments and oceanic observations, but with models acting as a bridge between the two.

An emphasis on validation can strengthen the working relationships among observationalists, experimentalists and modellers. Rigorous testing of modern coupled physical-biological models requires focussed experiments that result in high-quality data sets. However, achieving such data sets for a particular application will require close interaction between the modellers and the observationalists, because the answer to the question 'What observations are needed to test the model?' is neither simple nor obvious.

Questions related to the appropriate level of complexity can be addressed in a model validation framework. For a given model, any additional complexity which does not result in an improvement in the relevant skill metrics can be rejected. This is the same criterion used to evaluate whether an additional parameter should be added to a statistical model. The key is the multidisciplinary collaborations required to develop both skill metrics that are relevant to the problem at hand (and appropriate to the space and time scales of interest) and high-quality data sets, so that the decision to accept or reject particular changes to the model is meaningful.

\section{SPECIFIC ISSUES}

\section{Validating the equations}

A key component of model validation is demonstrating that the model equations properly reflect the dynamics that are deemed important. In their pioneering work on ecosystem models, Fasham et al. (1990) analysed their zooplankton model, which included 3 prey items, by considering the response to 1 type of prey when the other 2 types were set to zero (the implied single species resource response). The analysis identified sup-optimal feeding as a problem. If 2 prey items go to zero, then the zooplankton get less food from the third than if the model was written with only a single prey item. This anomalous behaviour has been largely ignored by the modelling community. Gentleman et al. (2003) provide a general framework for assessing the models of the functional response of zooplankton feeding on multiple prey categories. Using a set of 7 diagnostics, they show that the current formulations generally exhibit one or more anomalous dynamical features, such as sub-optimal feeding and negative switching. Negative switching occurs when an increase in the relative abundance of a prey species leads to a reduction in the relative contribution of that 
prey species to the diet of the predator. Gentleman et al. (2003) argue that the single most important diagnostic is the implied single resource response. These types of problems likely also exist in models where phytoplankton consume multiple nitrogen sources.

In the context of early life history models, Pepin (2004) observed that low growth rates were associated with high variance in growth and high growth rates were associated with low variance, in contrast to the common assumption that encounter rates follow Poisson statistics where the mean and variance are equal. The analyses of Gentleman et al. (2003) and Pepin (2004) reinforce the idea that when modelling PBI, where even the form of the equations is in doubt, analysis of sensitivity to changes in parameter values is not sufficient. Sensitivity to the form of the equations must be considered.

Most models of physical-biological interactions are written with the variables in concentration (or biomass) form (Eulerian models). The use of Lagrangian formulations (or individual-based models) has primarily been limited to detailed models of early life stages of larval fish (e.g. Werner et al. 2001) and of zooplankton (e.g. Carlotti \& Wolf 1998). Woods (2005) and Woods et al. (2005) provide a complete nutrient-phytoplanktonzooplankton ecosystem model based on the Lagrangian ensemble method, wherein ecosystem level questions can be addressed by examining individualbased formulations. This provides an opportunity to conduct numerical experiments that examine sensitivity to whether the equations are written in Eulerian or Lagrangian form and to understand the conditions under which one form is preferable to the other.

A specific modelling issue identified at WKFDPBI was the urgent need for guidance on how to organise organisms and groups of organisms into meaningful characteristic 'organisms' amenable to parameterisation and incorporation into models. The needs include information on when individuals rather than species need to be modelled and the extension of the concept of functional groups to account for the fact that as the bio-physical environment changes, the relative abundance of the species in the group may change and this will change the aggregated rate parameters.

\section{Model-data comparisons}

A first step towards a systematic approach to model validation is the routine use of skill metrics that account for both the differences between model and observations and the uncertainties in the observations. A good first step is the cost function approach, where the differences between the model and observations are scaled by the standard deviation of the observations. Moll
(2000) and Soiland \& Skogen (2000) used this approach to validate ecosystem models of the North Sea.

In many applications the biological signal of interest is largely boundary forced; this is particularly true in coastal areas with restricted exchange with the open ocean. In these cases the model is largely a mechanism for transforming the boundary conditions into observable biological quantities in the interior. At WKFDPBI, Paul Tett (pers. comm. 2004) argued that a test of model skill must remove the large boundary-forced signal and look at the residuals due to the interior dynamics. This separation of boundary-forced and interior dynamics is a more demanding standard than simply comparing model output with the observations and has the potential to shed new light on the quality of the nonlinear aspects of the model simulations. Laurent et al. (2006) used this approach in the validation of their model of a shallow Scottish Loch.

This separation of the boundary-forced and interior dynamics may also provide insight into where best to focus effort to improve the model. Consider an analogy with linear models, which are simply a mechanism for mapping initial conditions and boundary conditions to biologically relevant quantities in the interior. The goodness of fit to the observations cannot exceed that of a linear regression model based on the initial and boundary conditions. In Tett's analysis (pers. comm. 2004), the boundary-forced part of the solution is largely a linear (or weakly nonlinear) response, while the interior dynamics consists of nonlinear dynamical modes that give rise to variability that is independent of the boundary conditions. By analogy with the linear model, that portion of the observations that cannot be explained by the initial and boundary conditions is due to either internal dynamics or poor initial and boundary conditions. In the first case, the data set provides a basis for evaluating improvements to the model equations, and, in the second case, improvements to the simulations require either better observations of the initial and boundary conditions or more observations in the interior of the model domain that can be used to infer better initial and boundary conditions (data assimilation).

\section{Under-sampling in space, time and trophic structure}

At WKFDPBI there was a lively discussion centred on what is the best way to proceed given that the system will always be under-sampled in space, time, and trophic structure. There was no general resolution to this issue. Nevertheless, it was clear that the community must come to terms with the fact that there will always be important processes that cannot be completely represented mathematically. Limits will be imposed by spatial, temporal and trophic resolution 
and by limited knowledge. However, these unresolved processes can play fundamental roles in the ecosystem, and how they are dealt with can determine the success or failure of the model application. In the atmospheric community the effects of these unresolved processes are addressed by either sophisticated parameterisations based on detailed process knowledge or by using observations to constrain the evolution of the model dynamics (data assimilation). Systematic use of both approaches will be required for modelling physicalbiological interactions in oceanography.

A specific example of this issue was provided by Pepin (2004), who, in the context of larval fish models, addressed the question: 'Given the variability of prey concentration and the limited space and time resolution of the measurements, what is the likelihood of observing a relationship between growth and prey availability?' This required exploring the implications of the uncertainty in both models and data for interpreting the results of coupled biological-circulation models. Pepin's conclusion was that a probabilistic description of the environment and the larval fish life history was the way forward. The search for relationships between growth rates and prey concentration is further confounded by the potential for growth (and/or size)-dependent mortality (e.g. Otterlei et al. 1998, Pepin 2004), the fact that food abundance and food quality are not always related, and the fact that fast growth does not always imply survival (M. St. John pers. comm. 2004). In the latter case, ecological theory suggests that as food abundance increases, animals will spend more energy on predator avoidance and thus increase survival. Processes such as predator avoidance and food quality would also seem to require a probabilistic description in larval fish models.

\section{THE WORKSHOP ON ADVANCEMENTS IN MODELLING PHYSICAL-BIOLOGICAL INTER- ACTIONS IN FISH EARLY LIFE HISTORY (WKAMF)}

In this final section, I discuss a few of the ideas presented at the WKAMF and in the papers in this Theme Section as they relate to the themes of validation, complexity and integration.

In his review of coupled physical-biological models used to understanding fish recruitment, Miller (2007, this Theme section) found that, of the 64 articles reviewed (covering a period from 1993 to 2005), about $40 \%$ of the papers had progressed beyond using comparison with observations that were largely qualitative and were considering alternative mechanisms to explain the observations (either informally or by using formal null hypotheses). From the point of view of model validation, this seems very positive for the field.
A practical outcome of the workshop related to validation is the proposed paper on best practices for numerical methods for particle tracking that will include standard test cases. Particle tracking is often the simplest part of an early life history model and, while the theory is well established, there are numerous technical issues that can cause trouble, such as non-uniform diffusivity and land boundaries (B. Ådlandsvik unpubl.; see Table 1). A standard set of test cases will help modellers validate the particle tracking component of their models.

There is a definite trend towards increased complexity in early life stage models. This includes increased horizontal and vertical resolution in the circulation models and increased detail in the larval fish growth and development models. One factor driving the increased complexity is the fact that small changes in vertical location in the water column can dramatically change the drift path of a larva because of the horizontal and vertical shear in the ocean currents. Thus, 2 larvae separated initially by a few metres vertically can experience very different environments. As a result 'larval behaviour determines growth mortality and dispersal' (Fiksen et al. 2007, this Theme Section) and there is a strong drive to improve the simulation of the growth and behaviour processes (e.g. Leis 2007, this Theme Section). This generally leads to the requirement to simulate the lower trophic levels in order to provide prey fields for the larval fish (Peck \& Daewl 2007, this Theme Section, S. Hinkley et al. unpubl.; Table 1). As a result a reasonably simple model for the drift and dispersal of larval fish can evolve into an extremely complex modelling system with large demands for data, process parameterisation and validation.

The framework for simulating larval growth, development and interactions with prey items seems reasonably well established, although the details remain daunting. The next frontier in increased complexity is modelling mortality and predation (E. D. Houde unpubl., P. Pepin unpubl., A. Salthaug et al. unpubl.; Table 1). Pierre Pepin argued that the way forward will involve a probabilistic description of the predators and larval fish life history, similar to his proposal for modelling larval fish and their prey (Pepin 2004).

Some recruitment-oriented modelling shows movement towards limiting increases in complexity. The idea is to use the sophisticated models to identify the key processes and then base the recruitment model on either observations or simplified models (Brickman 2007, this Theme Section, G. Allain et al. unpubl.; Table 1). An extreme example of this is the Baltic cod recruitment model of Köster et al. (2001), in which the numerical models disappear entirely and the recruitment model is based on observational indices whose causal links to recruitment were established using 
Table 1. Authors and titles of presentations made at the Workshop on Advancements in Modelling Physical-Biological Interactions in Fish for which papers were not submitted to this Theme Section and which are referred to in the text

\begin{tabular}{|ll|}
\hline Authors & Talk title \\
\hline B. Ådlandsvik & The particle-tracking method for transport modelling \\
G. Allain, P. Petitgas, P. Lazure & A 'simple' biophysical model and its applications to anchovy in the Bay of Biscay \\
S. Hinckley, B. A. Megrey, A. J. Hermann, & Future directions in biophysical modeling: incorporating management needs into \\
C. Parada, W. Stockhausen & modeling strategies and the challenges ahead \\
E. D. Houde & Quantifying and modeling dynamic biological processes in fish early-life stages \\
P. Pepin & Modeling early life history losses to predators \\
A. Salthaug, G. Huse, M. Skogen & Is Norway pout recruitment affected by herring predation? \\
\hline
\end{tabular}

both observational analysis and numerical modelling. This approach of limiting complexity has several advantages, including reducing the need for data (relative to comprehensive ecosystem models) and allowing for quantitative validation and hypothesis testing.

The field of fish early life history models is well integrated with respect to physics and biology and the collaboration among observationalists, experimentalists and modellers. This is likely a legacy of the GLOBEC program, which established a framework in which the integration could occur. A second factor may be the obvious utility of larval drift and dispersion models to help interpret observations and explain patterns. The movement of early life stage modelling into larval behaviour and the need for modelling the prey items will require a significant expansion of the integration activities in order to bring together the expertise required to support all of the additional model components.

\section{CONCLUSIONS}

The issues of model validation, model complexity and the integration of physics/biology/chemistry, on the one hand, and observations/models/laboratory studies, on the other, are common across all the applications that fall under the umbrella of modelling physical-biological interactions in the marine environment. The process of model validation, thought of as a process of establishing limits to applicability, provides a framework for addressing diverse issues such as determining the appropriate levels of model complexity, and selecting appropriate equations and parameterisations.

A rigorous approach to model validation also forces the modellers to accept that marine observations and laboratory experiments are an integral part of the overall modelling process; knowledge advances in an iterative manner between the 3 groups. The scientific teams that lead the way to the future will be those able to organise in a way that moves knowledge and ques- tions rapidly between modellers, observationalists and experimentalists and results in the collection of data sets that allow model validation relevant to the problem at hand.

Several other important general points are:

(1) Unresolved processes will always be with us;

(2) The translation of the biological processes to mathematics and then to numerical model code must preserve the key elements of the biological processes (i.e. the math should not abuse the biology);

(3) Skill metrics are application dependent and need to account for the uncertainty associated with unresolved spatial and temporal variability of the biological system.

(4) Mortality, and predation in particular, is the next frontier in understanding the dynamics of fish early life stages.

Acknowledgements. On behalf of the members of the WGPBI, I thank Hans Dahlin, Tom Osborn and Harald Loeng for creating WGPBI and their inspired choice of a name. Thanks to the members of the WGPBI and the participants in the WKFDPBI and WKAMF for their insights and to ICES for providing a forum for discussion. Finally, I thank John Woods for his vision, clarity of thought and his passion for the topic of modelling physical-biological interactions.

\section{LITERATURE CITED}

Brickman D, Marteinsdottir G, Taylor L (2007) Formulation and application of an efficient optimized biophysical model. Mar Ecol Prog Ser 347:275-284

Carlotti F, Wolf KU (1998) A Lagrangian ensemble model of Calanus finmarchicus coupled with a 1D ecosystem model. Fish Oceanogr 7:191-204. doi: 10.1046/j.13652419.1998.00085.x

Dee DP (1995) A pragmatic approach to model validation. In: Lynch DR, Davies AM (eds) Quantitative skill assessment for coastal ocean models. American Geophysical Union, Washington, DC, p 1-14

deYoung B, Heath M, Werner F, Chai F, Megrey B, Monfray $P$ (2004) Challenges of modelling decadal variability in ocean basin ecosystems. Science 304:1463-1466

Fasham MJR, Ducklow HW, McKelvie SM (1990) A nitrogenbased model of plankton dynamics in the oceanic mixed layer. J Mar Res 48:591-639 
Fiksen Ø, Jørgensen C, Kristiansen T, Vikebø F, Huse G (2007) Linking behavioural ecology and oceanography: larval behaviour determines growth, mortality and dispersal. Mar Ecol Prog Ser 347:195-205

Gentleman W, Leising A, Frost B, Strom S, Murray J (2003) Functional responses for zooplankton feeding on multiple resources: a review of assumptions and biological dynamics. Deep-Sea Res Part II 50:2847-2875

Hannah CG (2003) Strategy for modelling physical-biological interactions. ICES CM 2003/P:04 (2003 ICES Annual Science Conference)

ICES (International Council for the Exploration of the Sea) (2001) Report of the study group on modelling physical/ biological interaction (SGPBI). ICES CM 2001/C:093. Available at: www.ices.dk/products/CMdocs/2001/C/ C0301.pdf

ICES (International Council for the Exploration of the Sea) (2002) Report of the study group on modelling physical/ biological interaction (SGPBI). ICES CM 2002/C:09. Available at: www.ices.dk/reports/occ/2002/SGPBI02.pdf

ICES (International Council for the Exploration of the Sea) (2003) Report of the study group on modelling physical/ biological interactions (SGPBI). ICES CM 2001/C:04. Available at: www.ices.dk/reports/OCC/2003/SGPBI03. pdf

ICES (International Council for the Exploration of the Sea) (2004a) Report of the working group on modelling physical/biological interactions (WGPBI). ICES CM 2004/C:03. Available at: www.ices.dk/reports/occ/2004/ WGPBI04.pdf

ICES (International Council for the Exploration of the Sea) (2004b) Report of the workshop on future directions in modelling physical-biological interactions (WKFDPBI). ICES CM 2004/C:02. Available at: www.ices.dk/reports/ occ/2004/wkfdpbi04.pdf

ICES (International Council for the Exploration of the Sea) (2005) Report of the working group on modelling physical/biological interactions (WGPBI). ICES CM 2005/C:04. Available at: www.ices.dk/reports/occ/2005/ WGPBI05.pdf

Köster FW, Hinrichsen HH, St John MA, Schnack D, MacKenzie BR, Tomkiewicz J, Plikshs M (2001) Developing Baltic cod recruitment models. II. Incorporation of environmental variability and species interactions. Can J Fish Aquat Sci 58:1534-1556

Editorial responsibility: Alejandro Gallego (Contributing Editor), Aberdeen, UK
Laurent C, Tett P, Fernandes T, Gilpin L (2006) A dynamic CSTT model for the effects of added nutrients in Loch Crenan, a shallow fjord. J Mar Syst 61:149-164

Leis JM (2007) Behaviour as input for modelling dispersal of fish larvae: behaviour, biogeography, hydrodynamics, ontogeny, physiology and phylogeny meet hydrography. Mar Ecol Prog Ser 347:185-193

Miller T (2007) Contribution of individual-based coupled physical-biological models to understanding recruitment in marine fish populations. Mar Ecol Prog Ser 347:127-138

Moll A (2000) Assessment of three-dimensional physicalbiological ECOHAM1 simulations by quantified validation for the North Sea with ICES and ERSEM data. ICES J Mar Sci 57:1060-1068

Otterlei M, Nyhammer G, Folkvord A, Stefansson SO (1998) Temperature and size-dependent growth of larval and early juvenile Atlantic cod (Gadus morhua): a comparative study of Norwegian coastal cod and northeast Arctic cod. Can J Fish Aquat Sci 56:2099-2111

Peck MA, Daewel U (2007) Physiologically based limits to food consumption, and individual-based modeling of foraging and growth of larval fishes. Mar Ecol Prog Ser 347:171-183

Pepin P (2004) Early life history studies of prey-predator interactions: quantifying the stochastic individual responses to environmental variability Can J Fish Aquat Sci 61: 659-671. doi: 10.1139/F04-078

Peters F, Hannah CG (eds) (2006) Special issue devoted to the Workshop on Future Directions in Modelling PhysicalBiological Interactions. J Mar Syst 61(3/4):115-274

Soiland H, Skogen MD (2000) Validation of a three-dimensional biophysical model using nutrient observations in the North Sea. ICES J Mar Sci 57:816-823

Werner FE, Quinlan JA, Lough RG, Lynch DR (2001) Spatiallyexplicit individual based modeling of marine populations: a review of the advances in the 1990s. Sarsia 86:411-421

Woods JD (2002) Primitive equation modelling of plankton ecosystems. In: Pinardi N, Woods JD (eds) Ocean forecasting. Springer-Verlag, Heidelberg, p 377-472

Woods JD (2005) The Lagrangian ensemble metamodel for simulating plankton ecosystems. Prog Oceanogr 67:84-159

Woods JD, Perilli A, Barkmann W (2005) Stability and predictability of a virtual plankton ecosystem created with an individual-based model. Prog Oceanogr 67:43-83

Submitted: June 20, 2006; Accepted: April 19, 2007

Proofs received from author(s): August 22, 2007 